\title{
Scenario Analysis of the Mobile Voice Services Market
}

\author{
HANNU VERKASALO*, KIM LINDQVIST, HEIKKI HÄMMÄINEN \\ *hannu.verkasalo@tkk.fi \\ +358405959663 \\ Helsinki University of Technology \\ Department of Communications and Networking \\ P.O. Box 3000, FI-02015 TKK, Finland
}

\begin{abstract}
Internet services shake the dynamics of the mobile industry. This paper studies the future of mobile voice with a scenario analysis method. A group of industry experts is interviewed to obtain a set of variables reflecting the uncertainties of the mobile voice market. These variables are used in describing the future evolution of mobile voice. With iterative interviews the two most important variables (mobile market structure and access mode in multi-radio networks) are defined, and four industry scenarios introduced. The mobile industry is found to be on a verge of horisontalization. The structural form of the market determines how mobile voice services are deployed in the future. The mobile industry is gradually moving towards the Internet. In this evolution, alternative wireless technologies are seen as the main source of disruption, with either one-operator or multi-operator terminal support. Also the regulation of mobile networks and services is found to play a significant role. Together the dominant market form (horizontal or vertical orientation) and techno-economic context (single-operator or multi-operator model) determine whether incumbent operators will retain strong position in the future.
\end{abstract}

Keywords: mobile voice, mobile Internet, mobile services, operator business

\section{Motivation}

Voice is still the most successful mobile service, and most of the operator revenue comes from circuit-switched mobile voice. However, for long the evolution of mobile networks has evolved towards packet-switched technologies, and today's new mobile devices enable seamless wireless Internet connectivity. According to Nokia's estimations, the number of mobile subscriptions is likely to surpass three billion in 2008 [1]. The number of Internet connections is much lower, about 1 billion in 2005 [2] [36]. The all-IP movement is taking place [3], pushing the Internet towards the mobile world. Consequently various kinds of Internet services from web browsing to email have emerged in the mobile domain [4], the mobile VoIP (mobile voice-over-IP), however, being still a newcomer service. 
The motivation to study mobile VoIP can be divided into three key trends that will inevitably take place in the mobile service domain: 1 . There will be a non-decreasing demand for mobile voice services; 2. Fixed-to-mobile substitution will evolve further; 3 . Packet-switched mobile connectivity will emerge. The biggest uncertainties regarding mobile VoIP include the business models to commercialize the IP-based mobile voice service and the players who will provision these services.

The current telecom world is characterized by a strong vertical orientation in which operators commonly run both the network and services [5]. Service innovation suffers because of the closed "walled garden" business models. The world of Internet is much different. This is because of two reasons. First, the end-to-end connectivity induces application-level development independent of the connectivity and networking layers. Second, the Internet services have evolved quickly mainly because of network-edge based innovation (i.e. the openness towards developers). The potential disruption resulting from the clash of the Internet and mobile telecom world is inevitable [6] [7]. Not only do individual companies face a new business environment in which to operate, but also the whole ecosystem experiences shocks, that might lead into new ways of doing business and serving end-users [8].

The mobile VoIP business presents an interesting playground as both incumbent telecom operators and challenger Internet players are providing IP-based voice [9]. Technically the uncertainty factors are low, and much more interest should be targeted at the potential business impact. Therefore the research question of the paper is: "What are the possible future scenarios of the mobile VoIP business?"

\section{Background}

\subsection{Industry structure and value networks}

Porter [10] models industry structures through his famous value chain framework. In the value chain framework Porter emphasizes the different stages that are needed in producing the final product from raw materials, as well as the division of company functions into core and support functions. In addition to core functions such as operations and sales, support functions such as $R \& D$ are typically needed in the process. Porter defines vertical integration as the extent of value chain coverage taking place inside one firm. In other words, companies that take care of a major part of the value chain are vertically integrated, whereas companies that focus on one part of the value chain only, contracting and outsourcing extensively with external companies, are not vertically integrated. In this paper operators are considered vertically integrated as they do play a role on many layers of the mobile service value chain, whereas Internet companies typically focus on services thus having less vertical integration. According to Kraft [11] the concept of vertical integration and its link to competitive dynamics is one of the major determinants of industry evolution.

Porter [10] makes a contribution by discussing vertical integration, industry structures and strategic role of firm boundaries. Harrigan [12] suggests that companies can apply various strategies, and the industry structure is an outcome of the strategic choices the individual companies apply in making up the ecosystem. Verkasalo [8] uses this theoretical background in comparing mobile business ecosystems in different countries against each 
other. He uses the term dominant market ecosystem in referring to the currently dominating form of the industry business ecosystem.

The complex production and business network management processes should be understood [13], and value networks are a more comprehensive metaphor than value chains. Mitchell and Singh [13] suggest that many approaches to vertical integration exist, and rather than choosing from two extreme choices companies should consider a whole portfolio of strategic paths. The concept of value chain cannot be easily used when analyzing industries [14], and therefore a more suitable term is value network. A number of studies exist applying or discussing value networks [15] [16] [17], one common thing being that they all consider value-creation dynamics as a more complex process than what the value chain framework suggests. In this paper, as the focus is on the role of mobile VoIP in transforming the mobile voice industry, the value network ideology with associated company clusters and hot-spots [18] is a natural approach. A business ecosystem is considered as a structured community of companies creating value [19. The term ecosystem highlights that all of the companies involved in the value-creation process are important in keeping the ecosystem alive. Ecosystems and other metaphors are needed when taking a holistic look at mobile industry evolution without focusing solely on one firm only [20].

\subsection{Cellular and Internet business ecosystems}

Operators deploy vertically oriented business models in the mobile industry. Cellular operators have invested in access and core networks, and they typically manage their networks quite independently. In some markets so called virtual network operators (MVNOs) have, however, emerged. MVNOs rent capacity from cellular network operators, and run their own subscriber management systems. So called service operators run their own brands and services only, their partners taking care of the technical infrastructure and network access. [21] [5] However, a typical cellular business ecosystem is vertically integrated. In many countries technical fragmentation exists (e.g. USA) thus making it difficult to achieve horizontal economies of scale in the mobile industry, whereas in some countries operators can lock the customer into their services by controlling, for example, the design of mobile terminals (e.g. Japan, see [7] and [22]).

The Internet world leverages modular technical infrastructures. PCs have spread all over the world, and operating systems in general support various add-on applications and open Internet networking. It is even difficult to define what the Internet is really all about. Email services, web browsing, streaming multimedia, instant messaging - they are all Internet services. Because of horizontally oriented technical and business architectures the innovative context is more open than in the mobile industry. People increasingly communicate with each other over the Internet (instead of only accessing content), and overlay networks (e.g. P2P and VoIP) are some of the most hyped new trends [23]. Innovative business approaches can be seen on the network edge (e.g. Skype leverages addon goods sales, and Google generates advertisement-based revenue). 


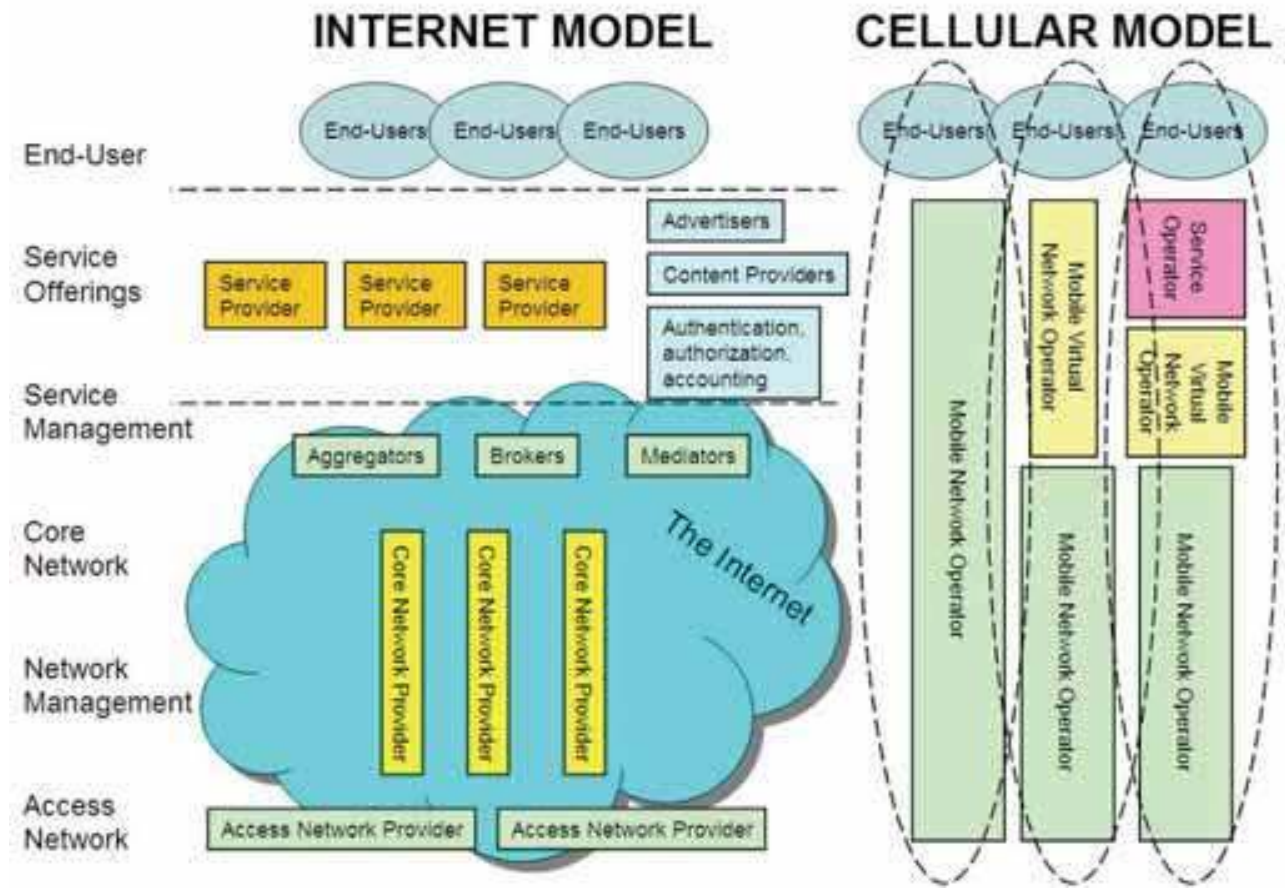

Fig. 1. - Internet vs. cellular model of service delivery

The figure above compares the different ecosystems. Though the illustration above is a simplification, the differences in the horizontal/vertical forms of the Internet and mobile industries are quite evident in practice. The difference in the market structure of these two industries is already pinpointed in [24] and [25].

\subsection{Disruptive potential of mobile VolP}

Christensen [26] introduces the idea of disruptive innovation. In a disruptive evolution initially a low cost challenger technology overtakes the dominant market technology, though the initial technical performance is inferior to the dominant design. From the business perspective disruptive services are considered as "...new services that create significant changes in a business model" [27]. Disruptive services shake dominant business models by introducing new innovations, at the same time making older services obsolete (consider e.g. Amazon's online book store). Hardagon [28] discusses breakthroughs, suggesting that radical innovations emerge typically when different worlds or paradigms are combined together. From this perspective the mobile Internet is an interesting concept. The mobile industry and the Internet business have emerged much separately from each other. Both industries generate significant producer and consumer surplus, in other words economic value-added. Radical potential exists if these two worlds are combined together. Ville Saarikoski [6] claims that indeed the mobile Internet could represent one of the radical forces transforming the incumbent business models of the mobile industry. 
Internet services represent potential sources of disruption in the domain of mobile services. As the dominant mobile business models in Europe are largely operator-centric, the emergence of the Internet business logic might weaken the power of operators and thus have an effect on the whole ecosystem. Data services provide the biggest venue for disruption, as the packet data interface to the Internet makes it possible for many of the known Internet services to be deployed in mobile handsets. Verkasalo [8] calls these as spillover effects of the fixed Internet. This also works the other way round. Incumbent mobile services can be replaced with Internet-based services. In this sense the mobile VoIP is an important topic, as the technical standards and solutions are ready (SIP; Skype; IMS, GAN), and voice is the most important (see the figure below) and widely used [4], still cellularbased, service used in mobile devices.

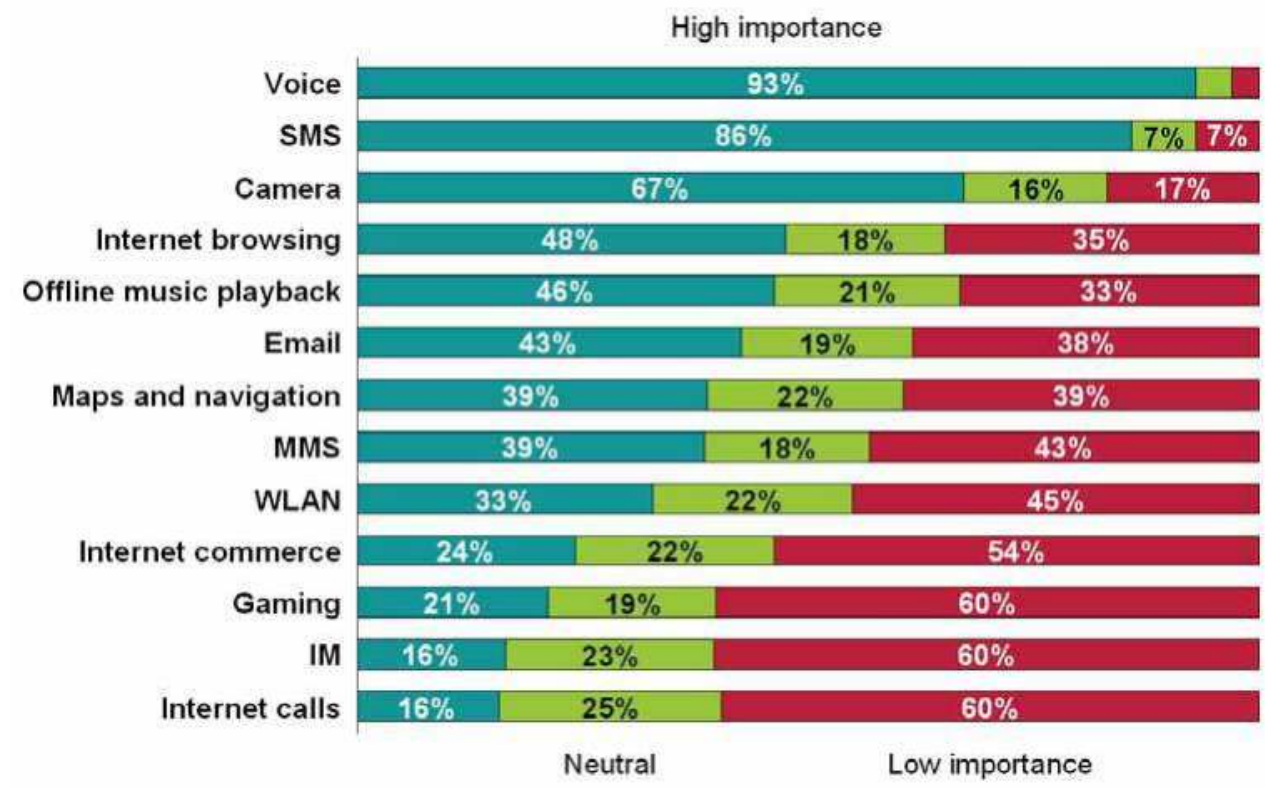

Fig. 2. - Importance of mobile services (adopted from the Finnish smartphone study 2007; [34] [35])

Along the lines of Christensen [26], challenger mobile VoIP services could in optimal conditions overtake the dominant circuit-switched voice service. The circuit-switched mobile voice already faces competition from Skype type of Internet solutions that complement the basic voice service with additional features such as chat, presence, voice mailbox and file transfer - all for free. A zero-cost alternative might catch interest in special circumstances at first, such as in international voice roaming [29].

As Figure 1 presents, the Internet model is horizontally layered. This means that the access and core networks are managed separately, and services are provided on top of the network. Little vertical integration exists. Overlay networks further utilize the horizontal structure of the Internet [23]. As the Internet is based on the layered OSI model [30], it is no 
surprise that also Internet business is much horizontally oriented with little vertical linkage between the actors of different layers. If this Internet model evades to the mobile domain, the most extreme outcomes would involve the break-up of the vertically oriented ecosystems. Alternative mobile access networks might emerge (e.g. WiFi, WiMAX), the business logic of incumbent cellular operators might change (orientation towards bit-pipe strategies), and services may be deployed on the edge of the network in the fashion of the Internet. Fixed-to-mobile Internet spill-over effects [8] and network externalities [31] are likely to drive the emergence of the mobile Internet. Most new data services have new value propositions. However, the mobile VoIP represents a perfect substitute to circuit-switched voice.

\section{Scenario Analysis of Mobile Voice Market}

\subsection{Scenario analysis method}

Scenario analysis is used in this paper to demonstrate how the long-term development of the mobile voice market can be modeled. The value-added of the scenario analysis is not in the final scenarios per se, but instead in the process of understanding on the one hand the fundamental drivers of the industry and on the other hand the new emerging forces shaping the business.

For scenario analysis, see [32] and [14]. In scenario analysis fundamental and certain drivers of the industry are first identified. In order to understand the uncertain, one has to first realize what is going to happen for sure. The underlying certain drivers include the nondecreasing need for voice services, migration from fixed to mobile services, and movement from circuit-switched services to packet data services.

In the second step of scenario analysis the underlying dynamic variables are identified. This can be done with, for example, expert interviews and Porter's five forces analysis. The objective is to come up with a list of uncertain variables that have an impact on the future. These variables are then grouped, dependencies between variables are controlled for by excluding dependent variables, and the most important uncertainties are constructed into key scenario variables that represent as the dimensions of the final model. The scenario analysis is iterative, and expert interviews are used to validate the developed framework. The interviews for this paper are held in Finland in June 2007, except for a preliminary interview with Ficora in February 2007. A list of interviewees is presented below.

\begin{tabular}{|l|l|l|}
\hline \multicolumn{1}{|c|}{ Name } & \multicolumn{1}{c|}{ Title } & \multicolumn{1}{c|}{ Company } \\
\hline Klaus Nieminen & Senior Adviser & Ficora \\
\hline Jaakko Kuosmanen & Managing Director & ICT Turku \\
\hline Juha Korsimaa & Senior Direc. Operat. & Fujitsu \\
\hline Tapani Nevanpää & Development Direct. & TeliaSonera \\
\hline Mika Julkunen & Project Manager & TeliaSonera \\
\hline Jarkko Utriainen & Head of Buss.Intellig. & DNA Finland \\
\hline Niklas Kolster & CEO & Ipon Communications \\
\hline
\end{tabular}

Table 1. - List of interviewees 


\subsection{Uncertain elements of structure}

The table below introduces the constructed uncertain elements of structure. They include all the uncertain elements of structure that affect the business around mobile VoIP.

Table 2. - Uncertain elements of structure of mobile VoIP

\section{Threat of new entrants}

- Do VoIP service providers pose a threat for the Finnish MNOs?

- Do international operators pose a threat for the Finnish MNOs?

- How will the regulation deal with proprietary voice services?

- Is the regulation of interconnecting PSTN and cellular changing?

- What is the significance of network effect of Internet communities?

- Will flat rate pricing introduce challengers on the service business?

- Does the mobile data access support all type of traffic?

\section{Bargaining power of buyers}

- How wide is the consumer/corporate demand for mobile VoIP?

- How price sensitivity affects the rate of switching a service?

- How do users adopt alternative roaming methods?

- Do the users deploy alternative mobile access technologies?

\section{Intensity of rivalry}

- How do the mobile operators' react with the Internet phenomenon?

- How are the license terms set for alternative wireless networks?

- Are the mobile operators going to deploy the alternative wireless technologies?

- Is the regulator going to continue handset bundling?

- Does the MNO's value reside on the network infrastructure or on the customer population?

\section{Threat of substitutes}

- What is the level of software modularity in mobile phones?

- Will service bundling become popular with handset bundling?

- Do alternative radio interfaces become popular on mobile phones?

- How do the Internet services affect the vertical mobile market?

- Do instant messengers pose a threat to voice services?

- Do switching costs have any significance on customer behavior?

- Is mobile VoIP able to replace or partially substitute CS voice?

- Are Internet businesses able to capitalize on the mobile market?

\section{Bargaining power of suppliers}

- Does the supplier group hold any potential entrants? 
- Are suppliers able to bypass the mobile operators in the value chain?

- Will the big suppliers support mobile VoIP on mobile handsets?

\subsection{Identifying the causal factors behind the scenario variables}

Before using the uncertainties in constructing the scenarios, the possible interdependencies between the variables need to be cut down. This is done by dividing the uncertainties into two categories. 1. Independent uncertainties: Those elements the uncertainty of which is independent of other elements of structure. The sources of uncertainty may be inside or outside the industry. 2. Dependent uncertainties: Those elements of structure that will be largely or completely determined by the independent uncertainties." Only independent variables can be used in scenario construction as they are not dependent on other variables. Dependent variables are set after the assumptions about independent variables are resolved. Each dependent variable then becomes part of the scenarios. [14]

The most important scenario variables are derived from the list of uncertain elements of structure by combining the relevant dimensions into a set of independent variables. Most of the uncertain elements of structure have synergies with each other and thus they need to be merged into consistent higher level variables. The six most important scenario variables that are formulated with this method (the first two are identified as the most important ones in the interviews) include:

1. What is going to be the dominating market structure?

2. What is the access mode in multi-radio networks?

3. What is going to be the pricing structure of mobile communications?

4. Is the market dominated by local or global service operators?

5. What is the level of consumer demand for alternative communication methods?

6. How is regulation of mobile telephony going to deal with the alternative mobile voice services?

The most important scenario variables are chosen to be the dimensions upon which the final scenarios are constructed. The chosen scenario variables of the future mobile VoIP business are here presented with the causal factors driving them. As Table 3 depicts, there are several causalities that underlie both scenario variables.

\begin{tabular}{|l|l|}
\hline Scenario Variable & Causal factors \\
\hline Market structure of mobile & - Do the international service providers or operators enter \\
industry & $\begin{array}{l}\text { - Winnish market? } \\
\text { alternative regulation support mobile voice service with the } \\
\text { - What is the level of software modularity in mobile } \\
\text { phones? } \\
\text { - What is the level of significance of Internet communities } \\
\text { and rich voice services? } \\
\text { - Does the MNO's value reside in the network } \\
\text { infrastructure or in the customer population? }\end{array}$ \\
\hline
\end{tabular}




\begin{tabular}{|l|l|}
\hline $\begin{array}{l}\text { Access mode in multi- } \\
\text { radio wireless networks? }\end{array}$ & $\begin{array}{l}\text { - How are the license terms set for access networks? } \\
\text { - Do the network providers choose to compete or } \\
\text { cooperate? } \\
\text { - Do alternative wireless technologies ever become a } \\
\text { success? } \\
\text { - Are the operators going to deploy alternative wireless } \\
\text { technologies? }\end{array}$
\end{tabular}

Table 3. - Causal factors determining the uncertainties of the mobile voice business

\subsection{Dimensioning the scenario variables}

Before introducing the final scenarios some dimensioning of the variables need to be conducted. Two most important scenario variables are dimensioned in two distinct dimensions. Firstly, the uncertainty in the dominating future market structure is dimensioned between vertical market structure and horizontal market structure. Secondly, uncertainty in the development of enabler technologies is dimensioned between singleoperator access mode and multi-operator access mode.

Market structure of the mobile industry is divided into two dimensions, even though the complexity of the variable enables a wider assessment, too. However, the current dimensioning is found essential in answering the question whether the dominating market structure is going to be horizontal or vertical. The mobile operators can either produce the VoIP services in-house and act also as content providers, or act only as network providers and give up in the services business. According to Vesa [5], vertical or horizontal market structure, together with the level of architecture modularity are the main dimensions that define the mobile market structure. In this paper the definition of market structure is, however, based on the distinction between vertical and horizontal orientation only.

In vertical market structure the first observation (and assumption also for the future) is that the convergence of the mobile industry (with the Internet) is currently rather weak, providing the incumbent operators' an asset to deploy mobile networks under their sole control. In Finland the status quo is mainly a closed group of mobile operators (DNA Finland, Elisa, TeliaSonera) who control the market and thus characterize the vertical form of mobile market structure. However, as more access networks emerge, the challenger players can provide comparable voice services in the mobile domain and thus challenge the mobile operators in mobile voice business. On the other hand, mobile operators are expected to provide mobile VoIP with GAN and IMS technologies to maintain their market dominance and avoid the threat of opening the walled gardens.

In horizontal market structure the convergence of mobile industries and mobile service providers is found significant, the synergy of alternative wireless communication channels and VoIP applications putting pressure on the dominance of mobile operators. New value networks, as presented in [33], are expected to leverage the potential for new innovations. In this sense, this paper observes not only the emergence of mobile VoIP, but also other internet services on mobile handsets. 
Horizontal market structure of mobile communications would be actually a continuation to the current wired broadband market in which the households are provided with connections of unlimited use with unrestricted content. The wired broadband market illustrates the structure of horizontal markets and justifies the expectations that the horizontal structure becomes dominating also in the mobile industry.

The perspective of access mode in multi-radio networks studies whether mobile phones enable multi-radio connectivity options. The uncertainty in this scenario variable derives from the fact whether the set of different radio technologies will be supported independently of each other or are they bundled together. Furthermore, the access mode variable holds also the uncertainty over whether the network selection is performed by the user or by the network itself. The uncertainty in this scenario variable is divided into two dimensions; single-operator access mode and multi-operator access mode.

The single-operator access mode describes the relationship of a network operator and multiple network access technologies. In the single-operator mode the mobile handset is able to access the network only through one predefined set of access technologies, the operatorcontrolled set of alternatives. Similarly, any network that is not managed by the network operator will not be accessible with the mobile phone. In single-operator mode the network interface of mobile handset is expected to be closed for any other network service than the one that is provided by the network operator. This has already been seen because of mobile operators that use SIM-lock on their bundled mobile handsets. Users may have some contribution to the selection as long as the selected network belongs to the predefined set of access networks. In single-operator mode the wireless networks are expected to operate cooperatively. Network based handovers are expected to be the key thing to make this work. Low-cost access technologies are favored and more expensive networks utilized only when needed. The system can, for example, favor WiFi over 3G and to utilize the latter only when the user misses WiFi coverage.

In the multi-operator mode the access networks and their providers are seen in a competitive context. Furthermore, in the multi-operator mode the network access selection is notably more open than in the single-operator mode. The horizontal market structure is favored in the multi-operator mode as voice services that support multi-operator mode are more likely horizontally layered than vertically integrated.

\subsection{Constructing the scenarios}

In order to construct the final scenarios, the two most important scenario variables are combined into internally consistent scenarios. The dimensioning, depicted below, describes the scenarios. The dimensions are combined into the final scenarios, presented as consistent combinations of the independent scenario variables. As presented in the figure below, four final scenarios are formulated 


\section{Access mode in multi-radio networks}

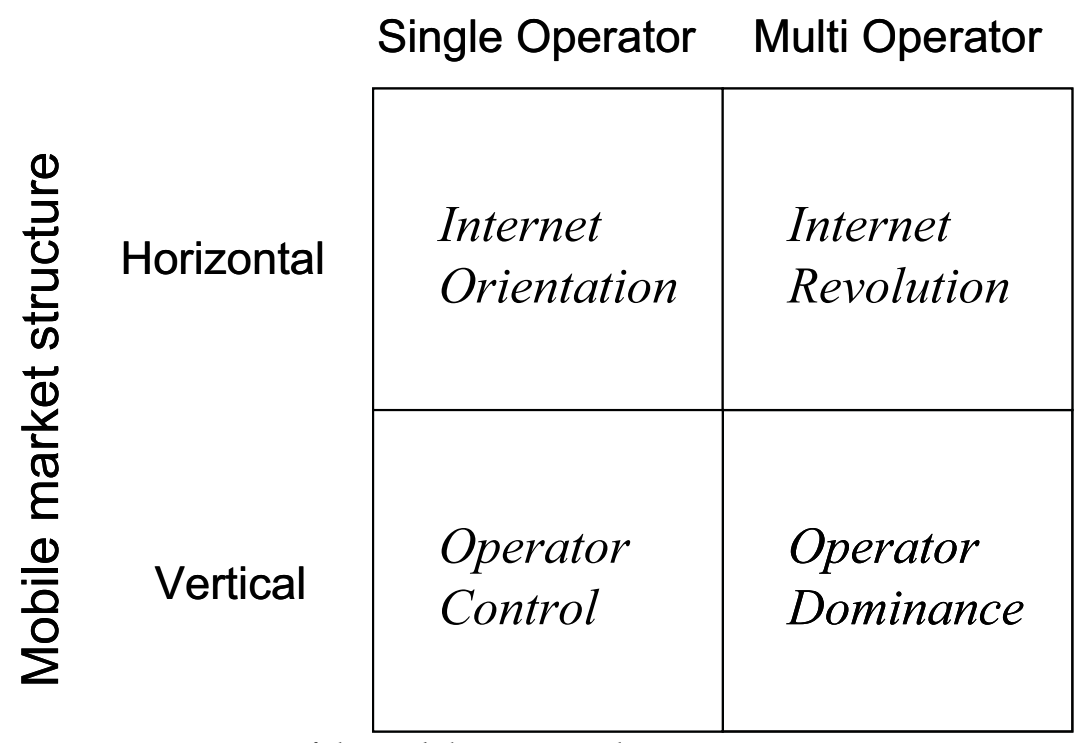

Fig. 3. - Future scenarios of the mobile voice market

\subsection{Scenarios of the future mobile voice market}

The initial setting on the current mobile industry forms a scenario that has not been defined with the formal scenario construction process. This scenario is, however, only a prolongation of the current situation in terms of the immaturity of the mobile VoIP business and thus also a continuation to the current vertical market structure. In the current situation the slowness of regulative decisions gives the mobile operators an asset to continue their current business models and prepare for future actions. At the same time VoIP service providers that still need to operate under the PSTN regulation are suffering from the slowdown of fixed telephony. This leads to a vanishing customer population and high interconnection costs from PSTN to cellular. In the current situation the high entry barriers keep the VoIP market unattractive for challenger VoIP service providers. The following sections present the special characteristics of the alternative scenarios. The scenarios are not projected to be mutually exclusive but rather to partially coexist.

This first scenario - operator control - continues partly from the current situation. In this scenario the market structure of the mobile industry is the same as now, meaning that the mobile operators have maintained their vertically integrated value networks by offering both the voice service and the network connections. Customers also call similarly as today, the only difference being that the terminal is able to deploy several different (operatorcontrolled) access technologies, with the condition that they are provided by the same operator. Terminals still require a SIM card or equivalent to operate (no multi-operator support). 
In Figure 4 (appendix) the operator A provides both the voice service and the network access. Several wireless technologies are supported, and also, as the distinction between VoIP and cellular is vague, it is presumable that a single subscription might be able to deploy both the CS voice and VoIP service in parallel. In this scenario the mobile operators are the strongest candidates in providing mobile VoIP, as they are currently the only players controlling wide area wireless networks (3G). However, the technical development with alternative wireless carriers poses this scenario a threat - challenger access providers being able to operate as a combined network access and VoIP operator, thus creating a competing service from the perspective of incumbent mobile operators. Similarly, the challenger wireless network operators are a threat when combined with an externally provided voice service. However, this setting leads the focus towards the scenario Internet orientation.

Emergence of alternative radio technologies poses this scenario a risk to either allow the market to reach a more horizontal structure. As the mobile industry obtains currently a vertically integrated structure, radical structural changes are not expected to happen rapidly. Thus the mobile operators will have good possibilities to organize their technologies and business models to better meet the future demand.

The second scenario - Internet orientation - assumes that the mobile industry converges with the Internet world. In this scenario the convergence of the industries is pushing the mobile industry to form a horizontal structure although the divergence and interoperability of wireless network technologies has not yet matured sufficiently to provide a ubiquitous wireless Internet. In this scenario the mobile operators are expected to head towards flat-rate pricing and perhaps ultimately also towards bit-pipe operator business models. Similarly, as with the previous scenario, the characteristic of this scenario is to be slightly fragmented between the old telecom world and new Internet world. However, the role of service providers is emphasized even more than in the previous scenario as the amount of services and applications is not limited to only one service operator. This scenario supports also the distinction between network operators and service providers the way they are presented in the Communications Market Act in Finland.

Figure 5 (appendix) illustrates the market dynamics of this scenario. Operator B is a virtual operator providing VoIP service to its customers, whereas operator $C$ has an exclusive right to provide the network access for the customers of operator B. More accurately, the operator $\mathrm{C}$ manages all the connections to the mobile handset, either due to legacy business models in mobile communications or due to monopolistic control over the various network technologies.

Compared to the current situation, the biggest difference in this scenario is the separation of the services industry and network business. In addition, a strongly tied relationship is expected to materialize between the end-user, and the network access provider instead of the voice service provider. Other than voice based mobile Internet services are expected to find this scenario rather attractive as the huge penetration of open mobile terminals with Internet connectivity opens a completely new market for them. If the horizontal market structure dominates the mobile industry, it would also imply that the future evolution leads 
towards the scenario Internet revolution - if the multi-operator access mode is being facilitated.

In the third scenario - operator dominance - the most relevant matter is the significant market power of mobile operators that is difficult to overtake by challenger actors. Mobile operators are considered vertically integrated in this scenario and a term master mobile operator is introduced to describe an operator that provides both the voice service and the network access. The main characteristic of this scenario, however, is the control over wireless technologies. Alternative networks that are not managed by the mobile operator are inaccessible with the mobile handset, if the end-user is willing to continue using the same voice subscription. In order to change the network provider, also the VoIP service should be changed. In other words the vertical silos take place, but on the other hand mobile terminals support multiple operators, and SIM cards (or equivalent) are not needed.

Figure 6 (appendix) illustrates the dynamics between the different operators in this scenario. Operator $\mathrm{A}$ is seen as a master operator in this scenario. Operator $\mathrm{C}$ is an alternative network access provider with whom the Operator A has made a contract so that Operator A's customers are able to deploy Operator C's network in places where Operator A has no network coverage. In an international level the cooperative contracting between network operators is better known as roaming agreements. On a national level the same concept is referred with a term national roaming. Regulation of communication markets on its current form supports this scenario. Pricing of interconnection and inability to route traffic to cellular networks are problems for new mobile VoIP service providers and proprietary solutions. If the competitiveness of these alternative services is hindered by the regulation it will lead to a situation where the mobile industry will not converge and the horizontal model will not dominate.

In the fourth scenario - Internet revolution - the market structure is strongly horizontal and the distinction between services and network accesses is clear. There are many ways to deploy mobile VoIP services; the end-user can either self manage both the VoIP service and the wireless network access selection, or the services can be combined by an external service aggregator. Furthermore, in the latter case the service aggregation can also be driven by the voice service provider or by the network operator. For example the network operator may recommend certain VoIP services alongside with the mobile network subscription. Or the other way round, the service provider may recommend certain network operators. The main characteristic of this scenario is, however, that the end-user may use several wireless network operators.

Figure 7 (appendix) illustrates this scenario. The end-user uses operator B's voice service but accesses the service through network operators A and C. Thus the market has horizontal structure and the user utilizes several network operators to access the voice service. Interoperability of the networks will probably set the highest demand for this scenario. Utilization of multiple access networks together with the support for seamless operability and mobile use will not be an easy task. Some sort of interoperability has been seen also in the previous scenarios as all the scenarios serve the idea of multiple radio interfaces. However, all the other scenarios more or less concentrate on providing the service within 
the same operator or within a collaboration of a set of operators. The scenario of Internet revolution assumes the access mode to be completely open and the services to be surrounded by a competitive context.

This final scenario itself is a bit vaguely defined, but it is also the most distinct to the current industry structure. Main issues rising in this scenario include the question of wireless connections taking over the wired connections. Other issues would be content-independent communications which will ultimately lead to a distinction of access providers and service providers and further to an issue of funding the services. Currently the VoIP telephony is riding on a crest of the wave by allowing free calls inside the VoIP domain. However, in the future this does not look promising and other revenue models need to be discovered.

\section{Conclusion}

Legacy cellular business ecosystems are much different from Internet ecosystems. Whereas strong operators have traditionally controlled mobile business ecosystems through vertical silos, Internet business models are horizontally oriented. Internet services are moving to the mobile domain due to the migration towards packet switched mobile networks. One of the most important mobile services is voice, which is likely to retain its fundamental position among communication services in the future, too. This paper sets out to model the future of mobile voice through scenario analysis.

The constituted future scenarios on the development of mobile voice communications describe the current market situation and mirror the future prospects of the evolving mobile voice market. All the scenarios are based on the findings of the analysis of business dynamics. The final outcome of the analysis is that the future market structure depends on two independent variables; mobile market structure and access mode in multi-radio networks. These variables are dimensioned into two to present prospective aspects of the market. Four final scenarios are formulated based on these dimensions.

First of the scenarios, operator control, continues closely from the current situation, the only difference being the expected emergence of mobile VoIP through multiple radio networks (all operated by the controlling operator). In this scenario the voice is not a separate service from the network connection. Instead, a scenario called Internet orientation is introduced to continue from the current situation with separation of service providers and network access providers. In these two scenarios the biggest difference is whether the mobile operator controls voice calls or whether the deployment of VoIP is open to rivalry. The common thing is that the network operator has a lock-in to the end-user (no multiple operators supported).

The two latter scenarios are partly continuations of the previous scenarios. Scenario operator dominance is probably most attractive for the mobile operators as it depicts the future to be fully controlled by the mobile operators, also in terms of controlling the VoIP usage. In this scenario, however, the terminals support multiple operators, leading the industry to a battle ground of few dominating operators operating vertical silos. Internet revolution is the opposite of operator dominance, stating the operators to be only bit-pipes and the actual 
service providers to be chosen by end-users. In the Internet revolution the use of open access networks is emphasized, which is not believed to be possible in the scenario operator dominance.

\section{References}

Nokia. (2005). Nokia defines strategy and targets for continued profitable growth. Press release, 1.12.2005. http://www.nokia.com/A4136002?newsid=1023902. Referred 20.2.2007.

Computer Industry Almanac Inc. (2005). Worldwide Internet Users Top 1 Billion in 2005. http://www.c-i-a.com/pr0106.htm. Referred 20.2.2007.

Alahuhta, P. \& Jurvansuu, M. \& Pentikäinen, H. (2004). Roadmap for network technologies and services. Tekes, Helsinki, Finland, Technology Review 162/2004. ISBN 952-457176-5.

Verkasalo, H. (2007). Insights on the Evolution of the Finnish Mobile Service Market. Submitted for publication at Conference on Telecommunication Techno-Economics CTTE) 2007, 14-15 June 2007, Helsinki, Finland.

Vesa, J. (2005). Mobile Services in the Networked Economy. IRM Press, Hershey, PA, USA.

Saarikoski, V. (2006). The Odyssey of the Mobile Internet. Doctoral Dissertation. University of Oulu, Finland.

Funk, J. (2004). Mobile Disruption - the technologies and applications driving the mobile internet, Wiley January 2004.

Verkasalo, H. (2007). A Cross-Country Comparison of Mobile Service and Handset Usage. Licentiate's paper, Helsinki University of Technology, Networking Laboratory, Finland.

Osterwalder, A. \& Ondrus, J. \& Pigneur, Y. (2005). Skype's disruptive potential in the telecom market: a systematic comparison of business models. HEC Lausanne Working paper, May 2005.

Porter, M. (1980). Competitive Strategy, Free Press, New York, 1980.

Kraft, J. (2003). Vertical structure of the industry and competition: An analysis of the evolution of the info-communications industry. Telecommunications Policy, 27, 625649.

Harrigan, KR. (1984). Formulating vertical integration strategies. Academy of Management Review, 9 (4), 638-652.

Mitchell, W. \& Singh, K. (1996). Precarious Collaboration: Business Survival after Partnerships shut Down of Form New Partnerships, Strategic Management Journal, 1996, 17.

Porter, M. (1985). Competitive Advantage, Free Press, New York, 1985.

Normann, R. \& Ramirez, R. (1993). From value chain to value constellation: Designing interactive strategy. Harvard Business Review, July-August 1993, 65-77.

Timmers, P. (1999). Electronic commerce - Strategies and models for business-to-business trading. London: John Wiley.

Berger, S. \& Sturgeon, T. \& Kurz, C. \& Voskamp, U. \& Wittke, V. (1999). Globalization, value networks and national models. Memorandum prepared for the IPC Globalization Meteting, October 8 (1999), MIT. 
Pursiainen, H. \& Leppävuori, I. (2002). Analysis of the Finnish mobile cluster - Any potential in mobile services. Helsinki: Ministry of Transport and Communications, Finland.

Moore, JF. (1993). Predators and pray: A new ecology of competition. Harvard Business Review, May-June, 75-86.

Afuah, A. (2001). Dynamic boundaries of the firm: Are firms better off being vertically integrated in the face of a technological change? Academy of Management Journal, 44 (6), 1211-1220.

Kiiski, A. (2007). Impact of Virtual Operators on Mobile Market. Licentiate's Paper. Networking Laboratory. Helsinki University of Technology.

Funk, J. (2006). Mobile phone industry: A microcosm of deregulation, globalization, and technological change in the Japanese economy. In R. Taplin (Ed.), Japanese Telecommunications Market and Policy in Transition. London: Routledge.

Clark DD. \& Lehr W. \& Bauer SJ. \& Faratin P. \& Sami R. \& Wroclawski J. (2006). Overlay Networks and Future of the Internet. Journal of Communications and Strategies, 3(63), pp 1-21, 2006.

Noam, EM. (1987). The Public Telecommunications Network: A Concept in Transition. Journal of Communication, Winter, pp.30-48.

Noam, EM. (1994). Beyond liberalization: From the network of networks to the system of systems. Telecommunication Policy, vol.18(4), pp.286-294.

Christensen, CM. (1997). The Innovator's Dilemma. Harvard Business School Press.

Barsi, T. (2002). Disruptive technology vs. disruptive applications. Telephony Online. http://telephonyonline.com/news/telecom_disruptive_technology_vs/index.html . Referred 6.6.2006.

Hargadon, A. (2003). How Breakthroughs Happen - The Surprising Truth About How Companies Innovate, Boston Massachusetts, Harvard Business School Press, 2003.

Kumar, RKR. (2006). International Mobile Roaming Alternatives: An Impact Analysis. Presented at World Telecommunications Congress 2006 - Emerging Telecom Opportunities. WTC, Budapest, Hungary, 1-3 May, 2006.

Zimmermann, H. (1980). OSI Reference Model - The ISO Model of Architecture for Open Systems Interconnection. IEEE Transactions on Communications, vol. 28, no. 4, April $1980, p p .425-432$.

Katz, ML. \& Shapiro, C. (1985). Network Externalities, Competition, and Compatibility. American Economic Review. American Economic Association, vol. 75(3), pages 424-40, June.

Karlson, B. \& Bri, A. \& Link, J. \& Lönnqvist, P. \& Norling, C. (2003). Wireless Foresight: Scenarios of the Mobile World in 2015. John Wiley and Sons, 2003.

Shapiro, C. \& Varian, HR. (1998). Information Rules: A Strategic Guide to the Network Economy. Boston, MA: Harvard Business School Press.

Verkasalo, H. \& Hämmäinen, H. (2007). A Handset-Based Platform for Measuring Mobile Service Usage. INFO: The Journal of Policy, Regulation and Strategy. Vol 9 No 1, 2007.

Verkasalo H. (2005). Handset-Based Monitoring of Mobile Customer Behavior. Master's Paper Series. Networking Laboratory. Department of Electrical and Telecommunications Engineering. Helsinki University of Technology.

ITU. (2007). Key Global Indicators for the World of Telecommunication Service Sector. Referred 1.9.2007. 


\section{Appendices}

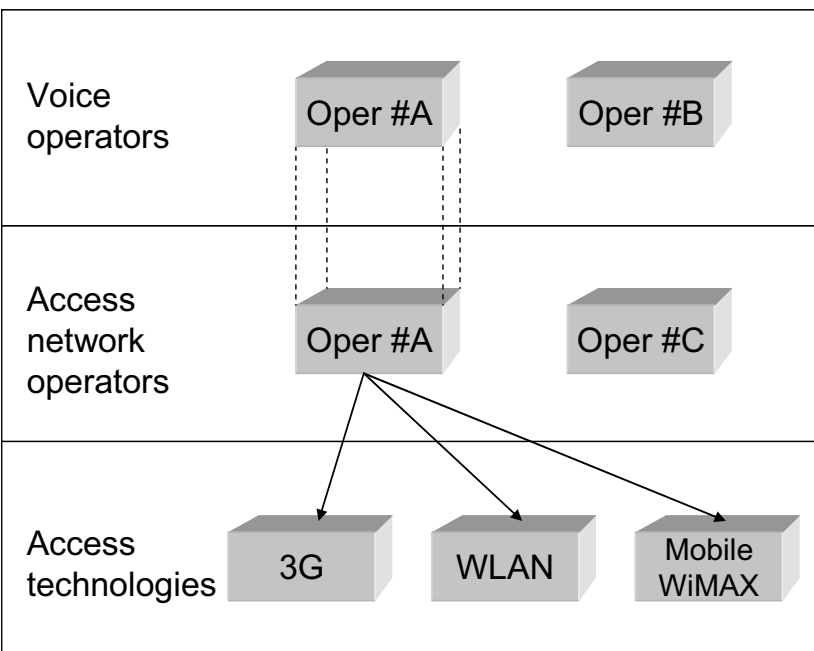

Market structure of

mobile communications

radio networks

Fig. 4. - Illustration of scenario "Operator control"

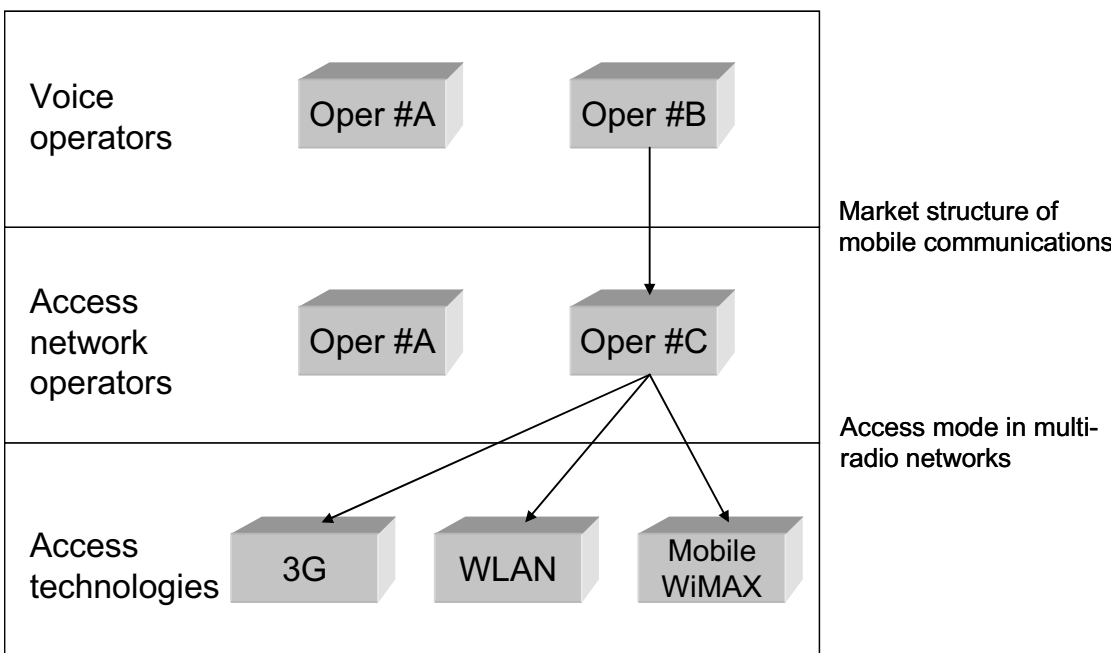

Fig. 5. - Illustration of scenario "Internet orientation" 


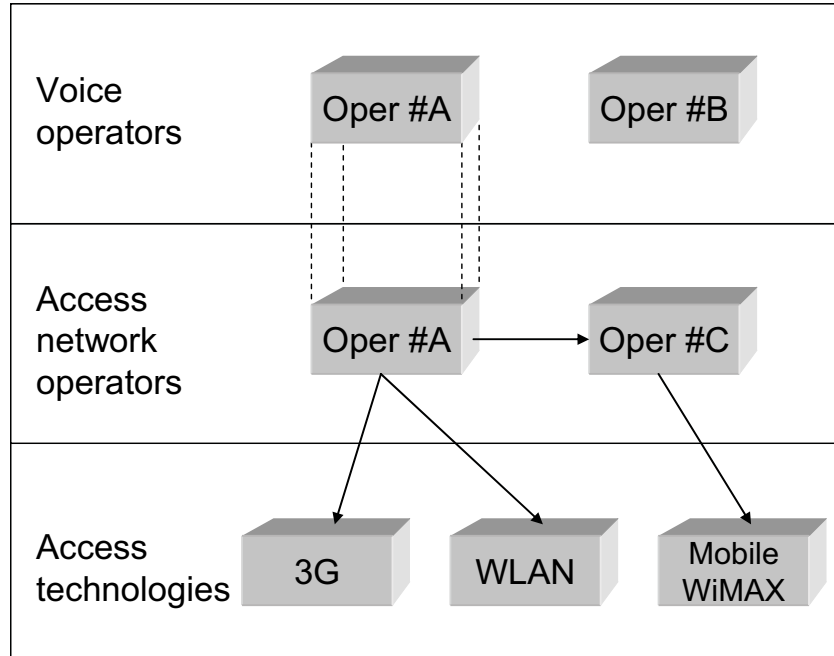

Market structure of

mobile communications

Access mode in multiradio networks

Fig. 6. - Illustration of scenario "Operator dominance"

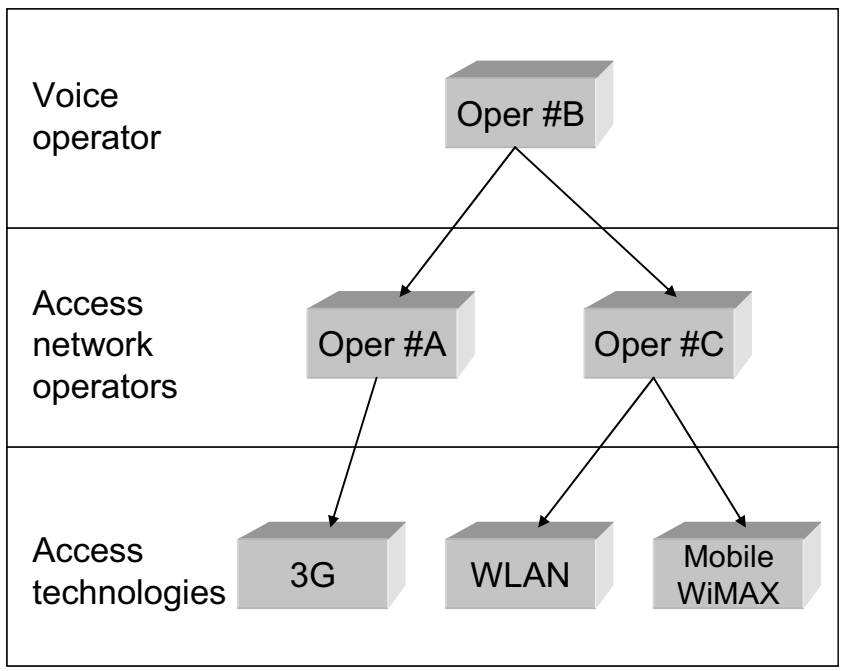

Market structure of mobile communications

Fig. 7. - Illustration of scenario "Internet revolution" mode in multiradio networks 


\section{Advances in}

Computer Science and IT

coman-

\section{Advances in Computer Science and IT \\ Edited by D M Akbar Hussain}

ISBN 978-953-7619-51-0

Hard cover, 420 pages

Publisher InTech

Published online 01, December, 2009

Published in print edition December, 2009

The book presents some very interesting and excellent articles for this divergent title. The 22 chapters presented here cover core topics of computer science such as visualization of large databases, security, ontology, user interface, graphs, object oriented software developments, and on the engineering side filtering, motion dynamics, adaptive fuzzy logic, and hyper static mechanical systems. It also covers topics which are combination of computer science and engineering such as meta computing, future mobiles, colour image analysis, relative representation and recognition, and neural networks. The book will serve a unique purpose through these multi-disciplined topics to share different but interesting views on each of these topics.

\section{How to reference}

In order to correctly reference this scholarly work, feel free to copy and paste the following:

Hannu Verkasalo, Kim Lindqvist, Heikki Hämmäinen (2009). Scenario Analysis of the Mobile Voice Services Market, Advances in Computer Science and IT, D M Akbar Hussain (Ed.), ISBN: 978-953-7619-51-0, InTech, Available from: http://www.intechopen.com/books/advances-in-computer-science-and-it/scenario-analysis-ofthe-mobile-voice-services-market

\section{INTECH}

open science | open minds

\section{InTech Europe}

University Campus STeP Ri

Slavka Krautzeka 83/A

51000 Rijeka, Croatia

Phone: +385 (51) 770447

Fax: $+385(51) 686166$

www.intechopen.com

\section{InTech China}

Unit 405, Office Block, Hotel Equatorial Shanghai

No.65, Yan An Road (West), Shanghai, 200040, China

中国上海市延安西路65号上海国际贵都大饭店办公楼 405 单元

Phone: +86-21-62489820

Fax: +86-21-62489821 
(c) 2009 The Author(s). Licensee IntechOpen. This chapter is distributed under the terms of the Creative Commons Attribution-NonCommercial-ShareAlike-3.0 License, which permits use, distribution and reproduction for non-commercial purposes, provided the original is properly cited and derivative works building on this content are distributed under the same license. 